\title{
Reviving Nursing Sector in India- A Sociologist's Perspective
}

\author{
C. Somashekher
}

Professor, Department of Sociology, Bangalore University, Bangalore-560056.

\begin{abstract}
Nursing which provides care for the sick and infirm, is one of the noblest professions in which nurses, committed to recoup the sick back to good health, performduties suppressing their obligations to family, sacrificing freedom to live a life of their own affecting their quality and conditions of life.In a populous country like India, the nursing profession plays an even more important role since owing to a very low ratio of nurses to the number of patients. This study reveals that poor training, outdated curriculum and the near absence of trained faculty in nursing colleges hobble the growth of nursing profession in the country. Naturally, good jobs are hard to come by for graduating nurses, most among whom eventually land up with contractual jobs. In other words, the supply glut is exploited by their employers to the hilt. Nurses are lacking in soft skills, with which they could have been more effective in dealing with the patients and in inspiring confidence in them. A sociological perspective in dealing with contemporary issues confronting the nursing sector appears to be very much called for. After all, the ability of nursing profession to positively impact the quality of life of nursing community canin turn enable the nursing community to improve their quality of service to the society as a whole, the findings seem to suggest that, among other things, the nursing community needs to be adequately and appropriately compensated and incentivized to ensure that at least the skilled and committed segment among them is retained in the interest of national health and national welfare.
\end{abstract}

Keywords: Complementarity; contractual jobs; dated curriculum; incentivise; supply glut

\section{INTRODUCTION}

India has always been a store house of nurses to the world at large (Nanki, 2016). Ironically, it is short of nurses on the home turf. Large number of hospitals complains that they have not been able to find qualified nurses. At the same time, any number of nurses coming out from nursing colleges complain that they have not been able to find suitable and adequate placements. But according to a FICCI-EY report the demand for trained nurses is expected to rise in the coming years, owing to the rising demand for tertiary and quaternary care in the country, India ranks $75^{\text {th }}$ in the list of 133 developing countries in respect of the ratio of nurse to population. There are only 0.7 doctors and 1.7 nurses available per thousand people. India needs over 2.4 million nurses to meet the growing demand.(The Nursing Times, 2017). This paradox can be attributed to several factors, as discussed in the following paragraphs. To sum up, one can state that all the stakeholders associated with the nursing sector are not even adequately satisfied.

\section{Statement Of The Problem}

Notable among the stakeholders who are not happy with the state of affairs prevailing in the nursing sector are the students pursuing the nursing course, their employers namely the hospitals and the career nurses. The nursing students complain that they are not being trained properly and to rub salt on to the wound, the components of the nursing curriculum have remained unrevised and un-updated for years. They accuse the employers or hospitals of taking undue advantage of the supply glut. On their part, the hospitals maintain that only a small chunk of the nurses who qualify are employable. They are not good enough to be on the rolls of state-of-the-art hospitals. Career nurses, on the other hand, see a sweatshop in the hospital they work for. It all boils down to one simple fact: the nursing sector as a whole needs to be revived promptly.

\section{REVIEW OF LITERATURE}

Despite being a major supplier of the health workforce, the health care industry in India is witness to a huge shortfall of nurses (The Nursing Times, 2017). The report "Nursing Reforms: Paradigm shift for 
a bright future" notes that the nursing sector in India continues to experience challenges in terms of availability, distribution and retention. A rewarding career progression for nurses is absent and issues like their individual welfare and income parity, among others, remain unattended. Additionally, alternative careers that promise superior rewards, a relatively safe work environment and opportunities to earn more abroad are engaging the attention of the nurses.

By default, at least in the Indian context, a nurse refers to a woman health worker and not a male health worker (Express News Service, 2017). But unobtrusively, men have been making their presence felt in the nursing sector owing to the reward it offers. Incidentally, the demand for male nurses is rather high, with more and more of aged patients seeking hospitalisation and with the rising demand for emergency services provided by hospitals. However, with overseas jobs offering superior rewards, experienced male nurses are inclined to work abroad. In Central Government services, nurses earn much more than what others earn. Nurses opting for nursing service in the armed forces enjoy the best pay and privileges. With the proportion of aging individuals rising in the country, leading to escalating demand for medical assistance, doctors believe that such migration-prone nurses should be retained in the country by offering them superior rewards. The demand in the country is very high for nurses in general and male nurses in particular, according to Doctors' Association for Social Equality. In fact, there is an alarming difference in the nurse to patient ratio. Ideally, it should be 1:6, but currently it stands at about $1: 40$ or $1: 60$ or sometimes even 1:80, according to a member of the Staff Nurses Union of a government hospital.

A good number of nurses from private institutions and many from government colleges enter the profession every year. However, only a few find permanent jobs (Sujatha, 2016). Poor salary and long working hours put off the nurses. Few hospitals employ the number of nurses that commensurate with the number of patients. Hospitals do not comply with the Indian Nursing Council's norms, for various reasons. The council stipulates that in the intensive medical care unit, each patient should have a dedicated nurse whereas in post-operative wards, there should be one nurse for every two patients. In the general ward, a nurse must attend to not more than three patients. According to an office-bearer of the Trained Nurses Association of India, though nurses are paid for their experience and the ward they mind, the demand for higher salaries has led hospitals to compromise on the quality of nursing and nursing personnel. Nurses from private hospitals seek jobs in government hospitals because of superior salaries, allowances and benefits. A home care nurse who works for 12 hours is paid INR. 650, where as the monthly salary in a private nursing home is only around INR. 4,500 for a fresher. Until hospitals realise that it is in their own interest to provide the best nursing care, nurses will not get a better deal, aver experts.

\section{RESEARCH GAP}

At least three important stakeholders associated with the nursing sector need to be focused upon if the sector as a whole has to be revived. Student nurses have to be helped to become more competent and state-of-the-art in their skills. Career nurses have to be persuaded to stay back in the country by offering them suitable incentives and compensation package. Hospitals have to be persuaded through a carrot-and-stick policy to extend a fair deal to career nurses and thereby, enhance the quality of health care they provide. Such a holistic approach is amiss in the discussions that figure in the reviewed literature. It is this gap the present study seeks to bridge.

\section{SCOPE OF THE RESEARCH}

The study confines itself to student nurses, career nurses and nurse consultants based in Bangalore (Rural) and Bangalore (Urban) districts. The issues discussed and analysed are pertinent and relate to Karnataka state in particular and the country in general.

\section{OBJECTIVES OF THE STUDY}

The objectives of the study are to:

1. Ascertain the factors that hobble the growth of nursing education in Karnataka in particular and India in general

2. Identify the problems faced by graduating nurses

3. Suggest the remedial measures needed to streamline the nursing sector 


\section{HYPOTHESIS PROPOSED TO BE TESTED}

The study proposes to test the following hypothesis:

"To deal with patients effectively and inspire confidence in them, nurses need to be equipped with soft skills"

\section{RESEARCH METHODOLOGY}

This is a descriptive study, involving investigations and adequate interpretation. Since it is a factfinding study, primary data havebeen collected through interview schedules from a sample of respondents. Non-parametric statistical units were used to test the associationbetween a few select qualitative characters and conclusions have been drawn on the basis of formation of $\mathrm{H}_{\mathrm{o}}$ and $\mathrm{H}_{1}$.

\section{SAMPLING PLAN}

Nursing students: Simple random sampling under the probability sampling method was undertaken to select the graduating nurses or nursing students at Bangalore city. Accordingly, Interview Schedules were distributed to 200 nursing students. The first 100 Interview Schedules received from the respondents, duly completed, were selected for the study.

Career nurses and Consultant nurses: Given the limited number of career and consultant nurses operating in the vicinity of the study area and the time constraint, purposive or judgement sampling under the non-probability method was employed to select the career and consultant nurses. Applying a minimum exposure of five years to services as criterion, the researcher selected 30 such respondents each from career and consultant nurses' category. This criterion, according to the researcher, is the most appropriate one for the present study. What is important is the typicality and the relevance of the sampling units to the study and not their overall representativeness to the population. Thus it guarantees the inclusion of the relevant elements in the sample. Probability sampling plans cannot give such a guarantee.

\section{Analysis of Primary Data}

\section{Analysis of Data on Student Nurses}

The primary data collected from the one-hundred nursing students is analysed and followed by the analysis on career nurses and consultant nurses.

\subsection{Factors that Hobble the Growth of Nursing Education in India}

The relevance of nursing education to a huge country like India hardly needs to be emphasised. Hence the researcher requested the respondents to mention the factors which according to them hobble the growth of nursing education in India. Their replies to the query appear in the following Table.

Table1. Factors that Hobble the Growth of Nursing Education in India

\begin{tabular}{|l|l|l|}
\hline Factors & Number of Respondents & Percentage \\
\hline Poor quality of the training imparted & 73 & $73 \%$ \\
\hline Out-Dated curriculum & 61 & $61 \%$ \\
\hline Absence of trained faculty at the college & 53 & $53 \%$ \\
\hline
\end{tabular}

The data presented in the table seem to indicate that poor quality of the training offered in the nursing colleges is the prime constraining factor in the growth of a well-trained and skilled nursing service though other factors like the redundant curriculum and absence of adequately trained faculty are almost as often cited factors as the quality of training. It may be observed that,a large majority (73 percent)of the respondents cite poor quality of the training imparted as a factorthat hobbles the growth of nursing education in India. Whereas 61 percent cite out-dated curriculum as a factor. Further, more than one-half (53percent) of them cite the near absence of trained faculty at the college. However, it is pertinent and significant to note that all the factors cited relate to the operation and management of nursing institutions. And as such the key lies with improving the overall standards of nursing education.

\subsection{Problems Faced by Graduating Nurses}

Graduating nurses face many problems. Hence the researcher requested the respondents to identifythe problems being faced by the graduating nurses, face. Their responses to the query are presented in the following Table. 
Table2. Problems faced by Graduating Nurses

\begin{tabular}{|l|l|l|}
\hline Problems & Number of Respondents & Percentage \\
\hline Good jobs are hard to come by & 74 & $74 \%$ \\
\hline Often employed on a contractual basis & 69 & $69 \%$ \\
\hline Employers exploit the supply glut & 59 & $59 \%$ \\
\hline Longer shifts and often, back-to-back shifts & 54 & $54 \%$ \\
\hline
\end{tabular}

About three-fourths (74 percent) of the respondents cite the fact that good jobs being hard to come by are a problem. Whereas 69 percent of them state that graduating nurses being employed on a contractual basis is a problem. However, 59 percent of them mentioned that employers exploit the supply glut. And 54 percent also cite longer shifts and often, back-to-back shifts as a problem.

It may be deduced from the data presented it the table above that it is not the actual working conditions that deter and bother the nurses but it is the nature and practices of employment by the recruiting agencies and institutions that render the nursing profession market driven and hence exploitative. It is also significant to note that despite huge shortage of trained nurses in India and in most part of the world, nurses suffer from absence or dearth of decent and acceptable job opportunities. The contractual nature of the employment that the majority of nurses have to cope up with, appears to be another major constraint in the growth so a healthy and efficient nursing profession.

\subsection{Measures to streamline the Nursing Sector}

With the respondents disclosing the factors that hobble the growth of nursing education in India and the problems faced by graduating nurses, the researcher requested them to suggest measures to streamline the nursing sector. Their replies to the query are given in the following Table.

Table3. Measures to streamline the Nursing Sector

\begin{tabular}{|l|l|l|}
\hline Measures & Number of Respondents & Percentage \\
\hline Update the curriculum & 89 & $89 \%$ \\
\hline Nurses to be equipped with soft skills & 80 & $80 \%$ \\
\hline $\begin{array}{l}\text { Nursing education to be in conformity with standards prescribed } \\
\text { by WHO and ICN. }\end{array}$ & 77 & $77 \%$ \\
\hline Ban quack nursing care and quack health care & 73 & $73 \%$ \\
\hline
\end{tabular}

According to the respondents, there appears to be an immediate need to update and upgrade the curriculum in vogue in the nursing institutions, which has not kept pace with the growing knowledge and sophistication in the field of medical care and treatment owing to which they appear to be incapable and incompetent in handling the day-to-day and routine hospital situations they find themselves dealing with. Further, with growing complexities of medical treatment and increasing application of latest medical technology for diagnosis, treatment and monitoring, the respondents emphasise the acquisition of requisite soft skills as indispensable and inevitable to survive in the profession of nursing. Thus the type of curriculum and the nature and extent of soft skills attained would determine their prospects of finding and pursuing a decent, meaningful and lucrative nursing profession. This is also reflected in over three-fourths of the respondents suggesting and insisting that the nursing education should conform and comply with the stringent standards prescribed by WHO and ICN. Another important suggestion seems to indicate to the wide prevalence of fake nursing personnel and fake nursing certification and the respondents appear to be advocating vehemently for a ban on such procedures and practices. In support of this argument, it may be observed that 89 percent suggest that the curriculum be updated. 80 percent want the nurses to be equipped with soft skills so they can deal with patients effectively and inspire confidence in them and 77 percent maintain that nursing education should conform to norms prescribed by the World Health Organisation (WHO) and International Council of Nurses (ICN). 73percent want quack nursing care and quack health care to be banned.

\section{Analysis of Data on Career Nurses}

In the following paragraphs, the primary data collected from the 30 career nurses are analysed.

\subsection{Factors that Hobble the Growth of Nursing Education in India}

The relevance of nursing education to a huge country like India hardly needs to be emphasised. Hence the researcher requested the respondents to reveal the factors that according to them hobble the growth of nursing education in India. Their replies to the query appear in the following Table. 
Reviving Nursing Sector in India- A Sociologist's Perspective

Table4. Factors that Hobble the Growth of Nursing Education in India

\begin{tabular}{|l|l|l|}
\hline Factors & Number of Respondents & Percentage \\
\hline Inability of nursing career to impact quality of life positively & 27 & $90 \%$ \\
\hline Out-Dated curriculum & 26 & $86.7 \%$ \\
\hline Poor quality of the training imparted & 25 & $83.3 \%$ \\
\hline Near absence of trained faculty at college & 25 & $83.3 \%$ \\
\hline
\end{tabular}

It may be noted that overwhelming majority (90 percent) of respondents expressed the factor of inability of nursing career to impact quality of life positively as the factor affecting nursing education in India. Sizeable proportion (86.7percent) of themconsider out-dated curriculum as a factor. Another sizeable proportion (83.3percent) of career nurses identified poor quality of the training imparted as a factor. As many ( 83.3 percent)of the respondents cite the near absence of trained faculty at the college as a factor.

Coming to the opinion of career nurses with regard to the factors that hinder healthy growth of nursing education in India, the findingsseem to indicate that a bleak prospect of a promising career, studded with achievements, accomplishments and advancements and assured higher quality of life,has been viewed as being responsible for the sorry state. It goes without saying that any branch of knowledge and system education that promises a bright career prospect thrives and those which do not offer such a prospect suffer decline and even may become extinct. Thus, those who are already serving as career nurses seem to be not happy or satisfied with rewards from nursing profession and hence consider it as a factor responsible for lapses in nursing education.Further, agreeing largely with the nursing students, an overwhelming majority of the career nurses opine that out dated and obsolete curriculum coupled with poor quality of training and absence or dearth of accomplished and trained faculty as factors responsible for the present sorry state of affairs with nursing education.

\subsection{Problems faced by Career Nurses}

Career nurses face many problems. Hence the researcher requested the respondents to reveal the problems the career nurses face. Their replies to the query appear in the following Table.

Table5. Problems faced by Career Nurses

\begin{tabular}{|l|l|l|}
\hline Problems & Number of Respondents & Percentage \\
\hline Sweatshop-like workplace conditions & 27 & $90 \%$ \\
\hline Employment on a contractual basis & 26 & $86.7 \%$ \\
\hline Longer shifts and often, back-to-back shifts & 26 & $86.7 \%$ \\
\hline Lack of Opportunities for higher and specialized education, & 26 & $86.7 \%$ \\
\hline Good jobs are hard to come by & 24 & $80 \%$ \\
\hline Career advancement remains a mirage & 23 & $76.7 \%$ \\
\hline
\end{tabular}

An overwhelming majority (90 percent) aver that sweatshop-like workplace conditions inflict musculoskeletal pain on them. Sizeable proportion (86.7 percent) cites that graduating nurses are often employed on a contractual basis. As many (86.7 percent) nurses cite that longer shifts and often back-to-back shifts pose a problem. Opportunities for higher and specialized education, continuing nursing education and research and development are hard to come by, aver 86.7percent. Further, 80percentof them state that good jobs are hard to come by. Similarly, more than three-fourth (76.7percent) of them state that career advancement remains a mirage.

The data presented in the table seem to indicate that the work life of nurses who toil to cure and recoup the sick and the weak, itself is rather sickening and does not present an enjoyable experience. An overwhelming majority of the career nurses state that it is like working in a sweatshop, with hectic schedule that literally leaves them badly shaken and exhausted, leading to musculoskeletal paid and disorders. Almost similar proportion of the career nurses tend to shun and complain about the exceptionally long working hours and to make it worse, they are compelled to work on back to back shifts. Other problems mentioned by the career nurses pertain to the nature and context of employment with large number of them being employed on contractual basis, with little job security and stunted career prospects resulting in their being victims of exploitative tendencies and practices. This could be attributed to the supply glut so widely prevalent in nursing profession with mushrooming of substandard, commercially driven and sometimes fake or unrecognized nursing institutions. It is rather pathetic and disappointing to note that, there are almost no opportunities and avenues for upgrading their knowledge and skills in specialized areas of nursing though health care 
and medical treatment as a sector is experiencing unprecedented sophistication and breakthrough in medical technology. The nurses having no access to advanced and specialized training fast become redundant and absolute, who could be of little utility in the state of art super speciality hospitals and hence are liable to be dispensed with or discarded. It is also significant to note that owing to the reasons mentioned above, a nursing career studded with promotions and advancement happens to be a mirage and a distant dream for the serving nurses, which has been experienced and expressed by overwhelming majority of the career nurses in the present study.

\subsection{Measures to streamline the Nursing Sector}

With the respondents disclosing the factors that hobble the growth of nursing education in India and the problems faced by graduating nurses, the researcher requested them to suggest measures to streamline the nursing sector. Their replies to the query appear in the following Table.

Table6. Measures to streamline the Nursing Sector

\begin{tabular}{|l|l|l|}
\hline Measures & Number of Respondents & Percentage \\
\hline Update the curriculum & 27 & $90 \%$ \\
\hline Equip nurses with soft skills & 27 & $90 \%$ \\
\hline Ban quack nursing care and quack health care & 27 & $90 \%$ \\
\hline Incentives to improve retention of skilled nurses & 26 & $86.7 \%$ \\
\hline $\begin{array}{l}\text { Nursing education should conform to norms prescribed by WHO } \\
\text { and ICN. }\end{array}$ & 25 & $83.3 \%$ \\
\hline
\end{tabular}

To streamline the nursing sector, overwhelming majority (90percent) of them suggest that the curriculum be updated. As many respondents want the nurses to be equipped with soft skills so that they can deal with patients effectively and inspire confidence in them. The same proportion (90percent) of them want quack nursing care and quack health care banned. Incentives will improve retention of skilled nurses and have a positive effect on recruitment, aver 86.7 percent of them. Sizeable proportion (83.3 percent) of them maintains that nursing education should conform to norms prescribed by the World Health Organisation (WHO) and International Council of Nurses (ICN).

The career nurses were asked to suggest measures that could improve and streamline the nursing sector. It is logically assumed that, these serving nurses being integral and indispensable part of the nursing sector could have valuable insights gained through first-hand experience and exposure to the limitations and vices of nursing profession and hence, can come out with suggesting measures that could be of immense practical, curative and applied significance in improving the conditions and effectiveness of nursing sector.

The findings seem to suggest that in tune with what the graduating nurses explain and opine, the most immediate measure that needs to be taken is updating and upgrading the curriculum of nursing courses so as to incorporate latest knowledge, skills and techniques in the medical field to keep the nurses coming out of these nursing institution abreast and apprised with what is latest in medical treatment and render them employable straightaway without additional training for orientation and refreshing. A similar proportion of the career nurses tend to emphasize the need for acquiring soft skills by the nurses to be effective operators and efficient practitioners of nursing profession in an era of state of art technology being invented and introduced in the field of medicine, failing which the nursing profession could experience layoffs and turnovers that are viewed as not conducive for any profession for that matter. Further to attract and retain the skilled and experienced nursing force, it is suggested to improve and enhance the compensation package for nurses and offer incentives in the form of overtime allowances, providing conveyance to work, making provision for looking after their tender ones while they are on duty, in addition to a good, reasonable and rational pay package. Lastly institutionalization and standardization of nursing education is suggested as a measure for enriching and elevating nursing profession. The standards and norms prescribed and mandated by the national and international regulating agencies must be ensured for unscrupulous compliance and adherence, so as to assure minimum standards and ethics of nursing profession, which in turn would ward off or atleast keep under check the quacks and fakes in nursing profession.

\section{Analysis of Data on Nurse Consultants}

In the following paragraphs, the primary data collected from the 30 nurse consultants is analysed and discussed. 


\subsection{Factors that Hobble the Growth of Nursing Education in India}

The researcher requested the respondents to state the factors which according to them hobble the growth of nursing education in India. Their replies to the query are presented in the following Table.

Table 7. Factors that Hobble the Growth of Nursing Education in India

\begin{tabular}{|l|l|l|}
\hline Factors & Number of Respondents & Percentage \\
\hline Inability of nursing career to impact quality of life positively & 27 & $90.0 \%$ \\
\hline Out-Dated curriculum & 27 & $90.0 \%$ \\
\hline Near absence of trained faculty at college & 27 & $90.0 \%$ \\
\hline Poor quality of the training imparted & 24 & $80.0 \%$ \\
\hline
\end{tabular}

An overwhelming majority (90 percent) of the respondents stated that the inability of nursing career to impact quality of life positively is a factor in flouncing nursing education in India. As many (90 percent) respondents opine that out-dated curriculum is also a responsible factor. Similar proportion (90 percent) state that near absence of trained faculty at the college as a factor. Further 80 percent of the respondents opine that cite the poor quality of training imparted is a factor responsible for poor state of nursing education in India.

Nurse consultants constitute and represent an important and integral segment, as well as dynamics of nursing profession. As such their conception and perception of issues and concerns pertaining to nursing education and nursing profession could provide valuable insight into the social and professional realities pertaining to nursing as a discipline and profession. As has been in the case of graduating nurses and career nurses, the nursing consultants were assigned to identify what according to them were the bane of nursing education in this part of the country. The data presented in table-7 indicates that even the nursing constants, seem to opine that the poor state of affairs with regard to so noble a profession like nursing is responsible for the nursing education, being in a state of decay and despair. A profession which was once looked upon as noble, respectable and lucrative has come to be known for exploitation, mediocrity, moral bankruptcy and as such a target for ridicule. It may be noted here, that a sizeable proportion of nurses lead a life characterized by poverty, destitution, physical and moral decay, suffering poor quality and standard of life. Human dignity and self-respect, for which this profession was known, has been eroded. This may also be attributed to the other lacunae of nursing education like out dated and redundant curriculum that makes little sense when it comes to equipping nurses of $21^{\text {st }}$ century with requisite knowledge, skill and aptitude for pursuing the profession in a manner that commands respect, reverence and appreciation. This situation is accentuated by the absence or acute shortage of qualified and experienced faculty in nursing institutions, owing to, as stated earlier, mushrooming of nursing institutions with less academic but more commercial orientation and motive, wherein, naturally the quality of training happens to be poor and far below norms and standards prescribed for compliance by regulatory agencies. In a way there appears to be high degree of consensus among the graduate students, career nurses and the nursing consultants so far as the factors that are exerting negative impact on the nursing education in this part of the country. However, the nursing consultants seem to be emphasizing the out-dated curriculum and absence of trained faculty as factors responsible for sorry state of affairs with nursing education more than the graduating nurses and the career nurses.

\subsection{Problems faced by Career Nurses}

Graduating nurses face many problems. Hence the researcher requested the respondents to reveal the problems the graduating nurses face. Their replies to the query appear in the following Table.

Table8. Problems faced by Career Nurses

\begin{tabular}{|l|l|l|}
\hline Problems & Number of Respondents & Percentage \\
\hline Sweatshop-likeworkplace conditions & 27 & $90 \%$ \\
\hline Lack of Opportunities for higher and specialized education, & 27 & $90 \%$ \\
\hline The supply glut & 25 & $83.3 \%$ \\
\hline Longer shifts and often, back-to-back shifts & 24 & $80 \%$ \\
\hline Employment on a contractual basis & 23 & $76.7 \%$ \\
\hline Career advancement remains a mirage & 23 & $76.7 \%$ \\
\hline Good jobs are hard to come by & 21 & $70 \%$ \\
\hline
\end{tabular}


An overwhelming majority (90 percent) of the respondents stated that sweatshop-like workplace conditions that inflict musculoskeletal pain on them is the problem. As many respondents ( 90 percent) aver lack of opportunities for higher and specialized education, continuing nursing education and research and development. Further, the supply glut is exploited by employers, as stated braver83.3 percent of the respondents. Whereas sizeable proportion ( 80 percent) of the respondents cite that longer shifts and often, back-to-back shifts pose a problem. Similarly, more than three-fourth (76.7 percent)of them state that career nurses are often employed on a contractual basis. Career advancement remaining a mirage cited as a problem by as many respondents (76.7 percent). And 70 percent of them cite good jobs being hard to come by is the problem.

With regard to problems being faced by the career nurses, as conceived by the nursing consultants, the data seem to indicate that inhuman and extreme working conditions of nurses are the major problems being faced by them. Equally serious according to them, are the constraints the serving nurses encounter in updating and upgrading their knowledge and skills through periodical advanced training and orientation. The nursing consultants seen to consider supply glut as another pressing problem that nursing professionals are facing. When the supply of human resources far exceeds the demand for the same, it is but natural that, those who are offering services are at serious disadvantage and tend to suffer exploitation and hardship. Further, as has been expressed and opined by the graduating nurses and the career nurses, the nursing consultants also believe that contractual nature of appointment and constraints on advancement in career, leading to despair and disappointment with regard to profession.

\subsection{Measures to streamline the Nursing Sector}

With the respondents disclosing the factors that hobble the growth of nursing education in India and the problems faced by graduating nurses, the researcher requested them to suggest measures to streamline and improve the nursing sector. Their replies to the query are as presented appear in the following Table.

Table9. Measures to streamline the Nursing Sector

\begin{tabular}{|l|l|l|}
\hline Measures & Number of Respondents & Percentage \\
\hline Update the curriculum & 27 & $90 \%$ \\
\hline Equip nurses with soft skills & 27 & $90 \%$ \\
\hline Ban quack nursing care and quack health care & 27 & $90 \%$ \\
\hline $\begin{array}{l}\text { Nursing education should conform to norms prescribed WHO } \\
\text { and ICN }\end{array}$ & 26 & $86.7 \%$ \\
\hline $\begin{array}{l}\text { Incentives to improve retention of skilled nurses } \\
\text { Nurses should be assured of minimum quality of life in line } \\
\text { WHO and ICN }\end{array}$ & 25 & $83.3 \%$ \\
\hline
\end{tabular}

With regard to streamlining the nursing sector, an overwhelming majority (90 percent) of the respondents suggest that the curriculum be updated and a similar proportion of respondents suggest that the nurses should be equipped with soft skills so they can deal with patients effectively and inspire confidence in them. Whereas similar proportion (90 percent) wants quack nursing care and quack health care to be banned. A sizeable proportion (86.7 percent) maintains that nursing education should conform to norms and standards prescribed by the World Health Organisation (WHO) and International Council of Nurses (ICN). Further,83.3 percent of the respondents are of the opinion incentives will improve retention of skilled nurses and have a positive effect on recruitment. A similar proportion of the respondents claimed that nurses should be assured of a certain level of quality of life in line with the recommendations of the World Health Organisation (WHO) and International Council of Nurses (ICN).

It is assumed that, measures and strategies that nursing consultants have to suggest, could be of greater practical and ameliorative impact, given their exposure, and experience in the field of nursing profession. As has been felt by the graduating nurses, and career nurses, updating and upgrading the curriculum holds the key to the problems and bane of nursing sector. Equally important is equipping the nurses with soft skills so essential and indispensable for pursuing nursing profession effectively and efficiently in the context of sophistication level that has come to be associated with this profession in contemporary times. According to the nursing consultants, it is also essential to see to it that, the nursing education as well as the rewards and compensations offered to the nursing professionals should be in conformity with the standards and norms prescribed by the statutory and 
Reviving Nursing Sector in India- A Sociologist's Perspective

professional regulatory agencies and institutions. They also seem to suggest that those in nursing profession need to be adequately compensated to see to it that nurses could enjoy a decent standard of living and have a reasonably good quality of life.

\section{HYPOTHESIS TESTING}

As already explained, the following is the hypothesis proposed to be tested:

"To deal with patients effectively and inspire confidence in them, nurses need to be equipped with soft skills"

Hence $\mathrm{H}_{0}$ and $\mathrm{H}_{1}$ are as follows:

$\mathrm{H}_{0}$ : "To deal with patients effectively and inspire confidence in them, nurses need not be equipped with soft skills"

$\mathrm{H}_{1}$ : "To deal with patients effectively and inspire confidence in them, nurses need to be equipped with soft skills"

On the basis of the primary data collected from the respondents, vide Tables: 3, 6 and 9, a chi-square test was applied to ascertain the association, if any, between the two variables, namely, the familiarity of nurses with soft skills on the one hand and the resultant ability to deal with patients effectively and inspire confidence in them on the other. The following Table reveals the computation made using MS-Excel:

\begin{tabular}{|l|l|l|l|}
\hline \multicolumn{5}{|l|}{ Observed Values } & Yes & No & Total \\
\hline Category & 80 & 20 & 100 \\
\hline Nursing students & 27 & 3 & 30 \\
\hline Career nurses & 27 & 3 & 30 \\
\hline Nurse consultants & 134 & 26 & 160 \\
\hline Total & \multicolumn{4}{|l|}{} \\
\hline Expected Values & Yes & No & Total \\
\hline Category & 83.750 & 16.250 & 100 \\
\hline Nursing students & 25.125 & 4.875 & 30 \\
\hline Career nurses & 25.125 & 4.875 & 30 \\
\hline Nurse consultants & 134.000 & 26.000 & 160 \\
\hline Total & Yes & No & \\
\hline \multicolumn{5}{|l|}{-3.7500} & 3.7500 & \\
\hline o-e & 1.8750 & -1.8750 & \\
\hline & 1.8750 & -1.8750 & \\
\hline & 14.0625 & 14.0625 & \\
\hline$(\mathrm{o}-\mathrm{e})^{\wedge} 2$ & 3.5156 & 3.5156 & \\
\hline & 3.5156 & 3.5156 & \\
\hline & 0.1679 & 0.8654 & \\
\hline$\left((\mathrm{o}-\mathrm{e})^{\wedge} 2\right) / \mathrm{e}$ & 0.1399 & 0.7212 & \\
\hline & 0.1399 & 0.7212 & 2.7555 \\
\hline CV & 0.4478 & 2.3077 & 5.991465 \\
\hline TV & & & 0.25 \\
\hline$p$ & & &
\end{tabular}

The calculated value of $\chi^{2}$ is 2.7555 , lower than the Table value of 5.991465 for an alpha of 0.05 at two degrees of freedom. Hence the null hypothesis is accepted and the alternate hypothesis is rejected. $\mathrm{p}=0.25$ is the inverse of the one-tailed probability of the chi-squared distribution. In other words, to deal with patients effectively and inspire confidence in them, nurses need not be equipped with soft skills

The analysis of association between the nurses being equipped with soft skills and their propensity and efficiency in dealing with their patients and boosting their confidence and trust in medical care and treatment as presented in the table seems to negate the hypothesis stated earlier, assuming a positive association between the two. It is rather interesting to note that an overwhelming majority that is more than 80 percent of the respondents belonging to all the categories, that is, the graduating nurses, career nurses and nursing consultants, believe and opine that soft skills are essential and compliment in rendering the nurses more effective and to facilitate in breeding confidence, trust and 
faith in patients. It also appears quite logical, rational and hence expected that in the wake of phenomenal advancement in medical science and medical technology, wherein application of ICT and computerized diagnostic treatment procedures and the state of art medical equipments instruments and gadgets, the nurses who have to operate and employ this technology have to be equipped with requisite soft skills as an imperative and essential condition and qualification. This being the situation, it appears quite logical to expect the nurses to be equipped with soft skills so as to not only instil confidence in the patients whom they treat but also to boost their own confidence or confidence in themselves to handle the complex medical cases. However, the analysis indicating no association or correlation between the two, much against what is assumed and presumed by the nursing personnel appears rather strange and hence needs further more focused research.

\section{Conclusion}

An attempt is made hereunder to summarise the major findings of the study so as to arrive at conclusions with predictive and suggestive value. It was found that an overwhelming majority of consultant and career nurses with their maturity and long association with nursing, compared to student nurses, were able to measure the impact and ascertain such factors as outdated curriculum, poor quality of training and absence of trained faculty responsible for hobbling growth of nursing education in India. With regard to problems and their seriousness, issues like supply glut, scarcity of good jobs, longer and back to back shift on the job were more strongly felt and experienced by the consultant and career nurses compared to novices like student nurses, However, almost equal proportion of student, career and consultant nurses suggested the measure of updating the curriculum with consensus for improving the state and quality of nursing education. Coming to suggestions, nursing colleges should take highest care in imparting quality training to student nurses. The regulating agencies like Nursing Council of India should monitor and ensure minimum standards of curriculum, instructions and internship components meticulously so as to see to it that the nurses coming out of these institutions are adequately trained for requisite knowledge, skills and professional aptitude and ethics. It is for the State government concerned and the Nursing Council of the State concerned to draw up an action plan for the purpose and execute it forthwith. Nursing colleges which are not in a position to impart quality training should be asked to wind up immediately. The Indian Nursing Council and the other regulators should ensure that only suitably qualified and trained teachers mentor the nursing students. Even if the college concerned is unable to hire trained teachers owing to valid reasons like non-availability of trained teachers, no latitude should be given to such violating colleges to continue to operate. As said earlier, the stakes involved are rather high, namely precious human lives. Longer shifts and back-to-back shifts do affect the nurses personally and professionally. If the nurse concerned renders deficient service owing to such reasons, it is the employer who should be blamed and held responsible and not the nurse concerned. Hospitals cannot expect an overworked nurse to work at the same level of efficiency beyond eight hours, as it tends to decline after the threshold level owing to stress, fatigue and strain. The researcher strongly recommends that the country's nursing education be benchmarked to comply with what the World Health Organisation (WHO) and International Council of Nurses (ICN) have prescribed as the minimum and mandatory standards for nursing education and the working conditions. This will automatically ensure that the country's nursing college products are of international quality. It will help them find highly remunerative jobs within the country and abroad. The researcher recommends that the nursing community be appropriately incentivised to ensure that at least the committed, motivated and skilled segment of nurses is retained in the interest of national health and by extension, in the interest of human welfare. Last but not least, the country can ill-afford quack nursing care and quack health care systems. It is surprising that the said quacks have a field day even in the $71^{\text {st }}$ year of the country's independence. This is unfortunate since this problem can be easily addressed given some seriousness on the part of the law and order machinery. Considering the havoc, the quack community can wreak on the gullible public, it is time the law enforcement agencies pulled up their socks and acted effectively in the matter.

The researcher confidently believes that these suggestions and recommendations are of applied, curative and ameliorative significance and hence can provide valuable insights and inputs for a sound policy on nursing education and nursing profession. If these suggestions are taken seriously and sincerely for implementation, it may bring about a sea change in the standards of nursing education being imparted in the country and consequently in the quality of nursing service available to the sick, infirm and the injured. 


\section{REFERENCES}

[1] Express News Service. (2017, February 8). Home: The New Indian Express. Retrieved from The New Indian Express web site: http://www.newindianexpress.com/states/tamil-nadu/2017/feb/08/gulf-betweenpay-opportunities-creates-male-nurse-shortage-in-tn-1568192--1.html

[2] Hiremath, S. L. (1994). Social Determinants of Job Satisfaction. International Sociological Association.

[3] Inkeles, A. (1960). Industrial Man: The Relation of Status to Experience, Perception and Value. American Journal of Sociology, 1-31.

[4] Mahua, V., \& Raj, K. R. (2017, March 2). Home: Hindustan Times. Retrieved from Hindustan Times Web site: http://www.hindustantimes.com/business-news/modi-s-demonetisation-move-will-positively-impacteconomy-world-bank-ceo/story-8Khb9U8UHOoEXoi75vyDfI.html

[5] Marc, F. (1973). The World of the Urban Working Class. Cambridge: Harvard University Press.

[6] Morse, N. C., \& Weiss, R. S. (1955). The Function and Meaning of Work and the Job. American Sociological Review, 191-198.

[7] Nanki, A. (2016, November 3). Home: inscol.com india blog. Retrieved from inscol website: http://www.inscol.com/india/blog/the-scope-of-nursing-in-india

[8] Prerna, K. (2017, February 27). Politics: livemint. Retrieved from livemint Web site: http://www.livemint.com/Politics/kQglM1kU5LSoF3IXZPImvO/Demonetisation-effect-economicgrowth-seen-slowing-to-61.html

[9] Sujatha, R. (2016, July 8). Cities: The Hindu. Retrieved from The Hindu Web site: http://www.thehindu.com/news/cities/chennai/dearth-of-talent-hits-nursing/article3606999.ece

[10] The Nursing Times. (2017, August 22). Home: The Nursing Times. Retrieved from The Nursing Times website: http://nursingexpert.in/india-need-additional-2-4-million-nurses-meet-demand/

[11] Tim, W. (2016, November 19). Economy: Forbes. Retrieved from Forbes Web site: https://www.forbes.com/sites/timworstall/2016/11/19/effects-of-demonetisation-on-indias-gdp-difficult-tocalculate-we-dont-even-know-the-sign/\#2531f6f67969

Citation: C. Somashekher. "Reviving Nursing Sector in India- A Sociologist's Perspective." International Journal of Research in Sociology and Anthropology (IJRSA), vol 3, no. 4, 2017, pp. 10-20. doi:http://dx.doi.org/10.20431/2454-8677.0304002.

Copyright:@ 2017 Authors. This is an open-access article distributed under the terms of the Creative Commons Attribution License, which permits unrestricted use, distribution, and reproduction in any medium, provided the original author and source are credited. 